\title{
The Functional Movement Screen total score and physical performance in elite male collegiate soccer players
}

\author{
Sungcheol Lee', Hyungjun Kim², Jooyoung Kim³,* \\ 'Department of Sports Leader, College of Sports Science, Woosuk University, Jeonju, Korea \\ ${ }^{2}$ Department of Physical Education, College of Natural Sciences, Kunsan National University, Gunsan, Korea \\ ${ }^{3}$ Department of Anatomy, School of Medicine, Kyungpook National University, Daegu, Korea
}

The objectives of this study were to compare the differences in physical performance of elite male collegiate soccer players according to the Functional Movement Screen (FMS) total scores and to investigate the association between the FMS total score and physical performance. A total of 20 elite male collegiate soccer players (mean age, $19.6 \pm 0.7$ years; height, $173.4 \pm 4.4 \mathrm{~cm}$; body weight, $66.9 \pm 7.3 \mathrm{~kg}$; and body mass index, $22.0 \pm 2.0 \mathrm{~kg} / \mathrm{m}^{2}$ ) participated in the present study. The subjects were divided into two groups: the high FMS (FMS total score $\geq 14$ points, $n=10$ ) and low FMS (FMS total score $<14$ points, $n=10$ ). All participants completed $10-\mathrm{m}$ and $30-\mathrm{m}$ sprint tests, the arrowhead agility test (right and left), and a coordination test. The statistical methods used to verify the study results were the independent sample $t$-test and Kendall's Tau b correlation test. There were significant differences be- tween the high and low FMS groups in the $10-\mathrm{m}(P=0.014)$ and 30-m sprint $(P=0.002)$ and arrowhead agility tests (right, $P=0.039)$. Conversely, there were no significant differences in the arrowhead agility (left) and coordination tests between the two groups $(P>0.05)$. Moreover, the FMS total score was found to have significant negative correlations with the 10-m sprint $(r=-0.444, P=0.017), 30-\mathrm{m}$ sprint $(r=-0.425, P=0.016)$, and arrowhead agility tests (right, $r=-0.389, P=0.023$ ). These results suggest that higher FMS total scores could have a positive effect on the physical performance of the players.

Keywords: Agility, Coordination, Functional Movement Screen, Physical performance, Soccer players, Sprint

\section{INTRODUCTION}

Soccer is a sport in which combinations of various physical fitness, including sprinting, changing direction, dribbling, walking, and running, occur repeatedly over a 90-min period (Lehance et al., 2009). To perform these actions at a high level, it is important to create optimal movement patterns based on the core, balance, range of motion, and coordination (Imai et al., 2014; Myer et al., 2005). However, poor movement patterns produce unfavorable biomechanical outcomes, which could ultimately increase the likelihood of minor or major injury (Cook et al., 2014), while also having a negative impact on the physical performance during matches (Chapman et al., 2014).

The Functional Movement Screen (FMS), which was developed by a physical therapist, Gray Cook, is a tool used to assess func- tional movement deficiencies based on proprioception, mobility, and stability (Cook et al., 2014; Frost et al., 2012; Kiesel et al., 2007). The FMS test is widely used for onsite assessment, owing to its characteristics of being low cost, simple, and noninvasive (Atalay et al., 2018). Surveys have confirmed that the FMS is the most commonly used method for establishing injury prevention strategies or testing injury risk in players belonging to soccer leagues in the United States and Australia (McCall et al., 2014).

Some studies have reported that low FMS total scores are associated with increased risk of injury (Chorba et al., 2010; Kiesel et al., 2007). According to Kiesel et al. (2007), there is a high likelihood of a serious injury to professional football players having an FMS total score of $\leq 14$ points. Additionally, Chorba et al. (2010) reported that the risk of lower extremity injury increased by 4 -fold in athletes with an FMS total score of $\leq 14$ points. Therefore, the
*Corresponding author: Jooyoung Kim (iD https://orcid.org/0000-0002-0526-6559 Department of Anatomy, School of Medicine, Kyungpook National University, 680 Gukchaebosang-ro, Jung-gu, Daegu, 41944, Korea

E-mail: hirase1125@hanmail.net

Received: July 31, 2019 / Accepted: September 4, 2019
This is an Open Access article distributed under the terms of the Creative Commons Attribution Non-Commercial License (http://creativecommons.org/licenses/by-nc/4.0/) which permits unrestricted non-commercial use, distribution, and reproduction in any medium, provided the original work is properly cited. 
FMS total score has thus far been used as a predictor of injuries among athletes, and several studies have investigated its association with injuries (Bonazza et al., 2017; Mokha et al., 2016; Smith and Hanlon, 2017).

In contrast, it is still questionable as to whether the FMS total scores of athletes are actually associated with their physical performance. While some studies suggest that athletes' FMS total scores of are significantly associated with their physical performance (Atalay et al., 2018; Lloyd et al., 2015), others have reported contradicting results, indicating no association between the two (Silva et al., 2017). Moreover, these studies were based on populations that differed greatly from one another, for example, the participants investigated by Atalay et al. (2018), Silva et al. (2017), and Lloyd et al. (2015) consisted of handball players, surfers, and young soccer players aged 11-16 years, respectively.

Accordingly, the objectives of the present study were to compare the differences in physical performance of elite male collegiate soccer players according to FMS total scores and to investigate the association between the FMS total score and physical performance.

\section{MATERIALS AND METHODS}

\section{Subjects}

The study population consisted of 20 elite male collegiate soccer players (mean age, 19.6 \pm 0.7 years; height, $173.4 \pm 4.4 \mathrm{~cm}$; body weight, $66.9 \pm 7.3 \mathrm{~kg}$; and body mass index, $22.0 \pm 2.0 \mathrm{~kg} / \mathrm{m}^{2}$ ) from Munkyung College (Mungyeong, Korea). The subjects had no musculoskeletal injuries in the upper or lower extremities at the time. Each subject had the objectives and procedures of the study explained to them and voluntarily signed an informed consent form. The subjects were divided into two groups: the high FMS (FMS total score $\geq 14$ points, $n=10$ ) and low FMS (FMS total score $<14$ points, $n=10$ ) groups. The characteristics of the subjects are shown in Table 1.

Table 1. Characteristics of the subjects

\begin{tabular}{lccl}
\hline Variable & High FMS $(\mathrm{n}=10)$ & Low FMS $(\mathrm{n}=10)$ & $P$-value \\
\hline Age $(\mathrm{yr})$ & $19.6 \pm 0.6$ & $19.6 \pm 0.8$ & 1.000 \\
Height $(\mathrm{cm})$ & $173.5 \pm 3.5$ & $173.4 \pm 5.4$ & 0.962 \\
Body weight $(\mathrm{kg})$ & $65.1 \pm 4.7$ & $68.7 \pm 9.1$ & 0.289 \\
Body mass index $\left(\mathrm{kg} / \mathrm{m}^{2}\right)$ & $21.4 \pm 1.2$ & $22.6 \pm 2.6$ & 0.203 \\
FMS total score & $15.3 \pm 1.2$ & $10.5 \pm 1.6$ & $0.000^{* * *}$ \\
Deep squat & $2.0 \pm 0.8$ & $1.2 \pm 0.4$ & $0.013^{* *}$ \\
Hurdle step & $1.6 \pm 0.6$ & $1.0 \pm 0.4$ & $0.039^{*}$ \\
In-line lunge & $2.4 \pm 0.6$ & $1.3 \pm 0.4$ & $0.001^{* * *}$ \\
Shoulder mobility & $2.2 \pm 1.0$ & $1.0 \pm 0.0$ & $0.005^{* *}$ \\
Straight leg raise & $2.4 \pm 0.6$ & $2.5 \pm 0.5$ & 0.722 \\
Trunk stability push-up & $2.5 \pm 0.5$ & $2.2 \pm 0.6$ & 0.264 \\
Rotary stability & $2.0 \pm 0.0$ & $1.9 \pm 0.3$ & 0.343
\end{tabular}

Values are presented as mean \pm standard deviation.

FMS, Functional Movement Screen.

Tested by independent sample t-test. ${ }^{*} P<0.05$. ${ }^{*} P<0.01$. ${ }^{* *} P<0.001$.

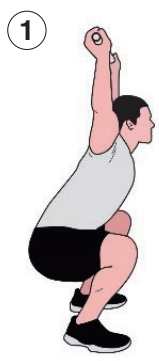

Deep squat

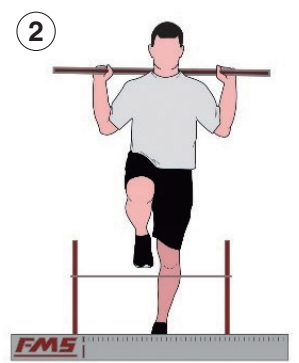

Hurdle step
(3)

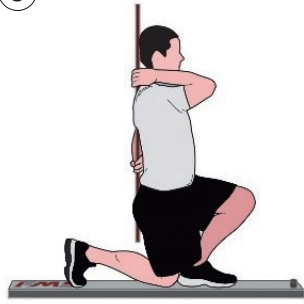

In-line lunge
(4)

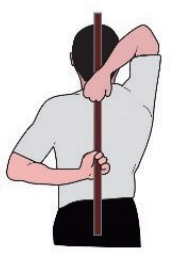

Shoulder mobility
(5)

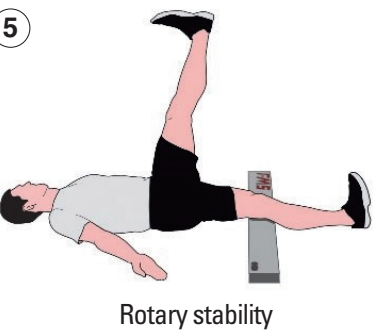

(6)
(7)

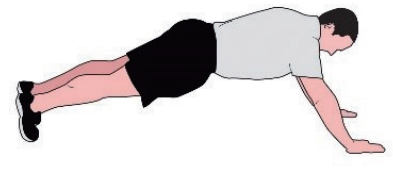

Active straight leg raise

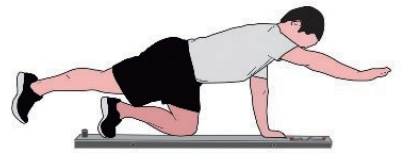

Trunk stability push-up

Fig. 1. Seven tests of Functional Movement Screen. 


\section{The Functional Movement Screen}

The official tool for the FMS (Functional Movement Screen Test Kit, Functional Movement System, Chatham, VA, USA) was used to measure (a) deep squat, (b) hurdle step, (c) in-line lunge, (d) shoulder mobility, (e) active straight leg raise, (f) trunk stability push-up, and (g) rotary stability (Fig. 1). When shoulder mobility, trunk stability push-up, and rotary stability were being measured, clearing tests were performed together. Cook et al. (2014) were referenced for the detailed measurement methods for each variable. The motions involved in each movement were performed repeatedly, three times each, and the motion of the subject was graded on a scale of $0-3$ points. The FMS scoring criteria were as shown in Table 2. The maximum possible score by the FMS was 21 points and the measurements were taken by an FMS specialist with several years of experience.

\section{Physical performance}

In this study, physical performance was measured based on 10-m and 30-m sprints, agility, and coordination. For accurate measurements, electronic timing devices (Brower TC, Brower Timing Systems, Draper, UT, USA) embedded with automatic sensors were used which were set up on the start and finish lines. All items were measured by a single researcher to ensure reliability of measurements. Prior to the measurements the subjects performed 20 min of warm-up exercises including running. For all measurements and procedures, Joo (2016) and Lockie et al. (2018) were referenced.

\section{0-m and 30-m sprint test}

The subjects waited in standing position $50 \mathrm{~cm}$ behind the start line before starting, and when signaled by the researcher, they sprinted at full speed to $10-\mathrm{m}$ and $30-\mathrm{m}$ and crossed the finish line. The 10-m and 30-m sprint times were measured twice each, and the fastest time for each distance was used as the final record.

\section{Arrowhead agility test}

The subjects waited $50 \mathrm{~cm}$ behind the start line in standing position before starting. When signaled by the researcher, they

Table 2. Functional Movement Screen scoring criteria

\begin{tabular}{ll}
\hline Score & \multicolumn{1}{c}{ Criteria } \\
\hline 3 & Complete movement without any compensation \\
2 & Perform movement with compensation \\
1 & Unable to perform movement \\
0 & Pain with perform movement \\
\hline
\end{tabular}

started towards cone $\mathrm{A}$, which was placed $10 \mathrm{~m}$ away; moved to cone $\mathrm{B}$ located $5 \mathrm{~m}$ away; moved back to cone $\mathrm{C}$; and crossed the finish line (Fig. 2). The same method was used for testing both the left and right sides. Each test was performed twice, and the fastest time recorded for each participant was used.

\section{Coordination test}

The subjects waited standing $50 \mathrm{~cm}$ behind the start line before starting, and when signaled by the researcher, they passed all the cones while dribbling a ball. Once they reached the final cone, they went back to the start line, dribbling the ball in the same manner (Fig. 3). If a subject touched a cone or did not pass through properly, a penalty of 2 seconds was added to their total. The test was performed twice, and the fastest time noted for each participant was used.

\section{Statistical analysis}

The results are expressed as mean \pm standard deviation. Independent sample $t$-tests were performed to compare the differences in the characteristics of participants and physical performance (10-m and 30-m sprints, agility, and coordination) between the two groups according to the FMS total scores. Moreover, Kendall's Tau b correlation test was performed to analyze the association between the FMS total score and physical performance (10-m and 30-m sprints, agility, and coordination). Statistical analyses in the study were performed using IBM SPSS Statistics ver. 21.0 (IBM Co., Armonk, NY, USA) with the statistical significance level set to 0.05 .

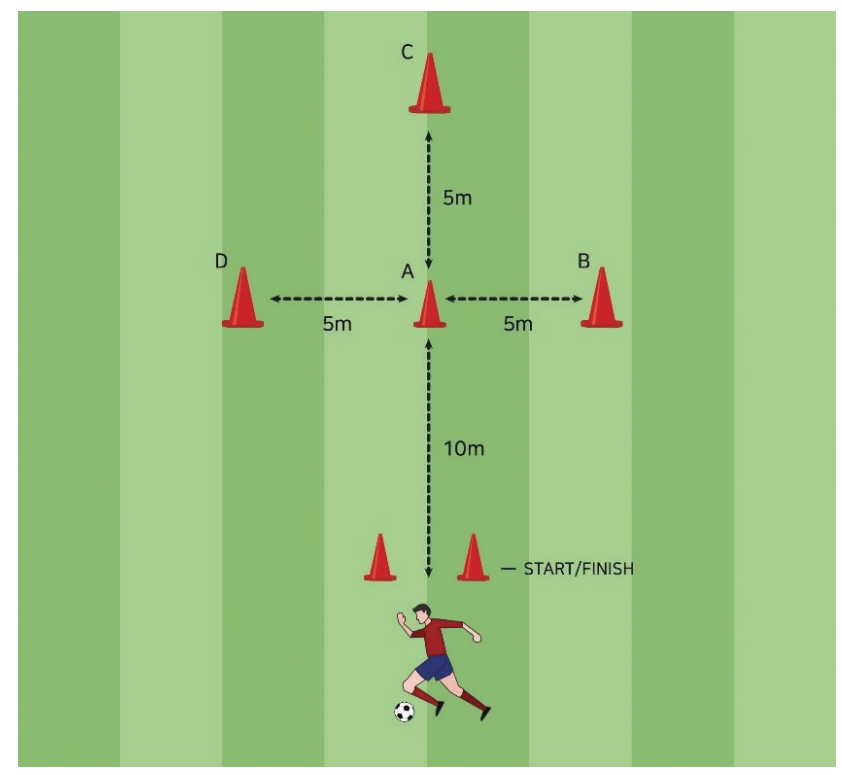

Fig. 2. Arrowhead agility test. 


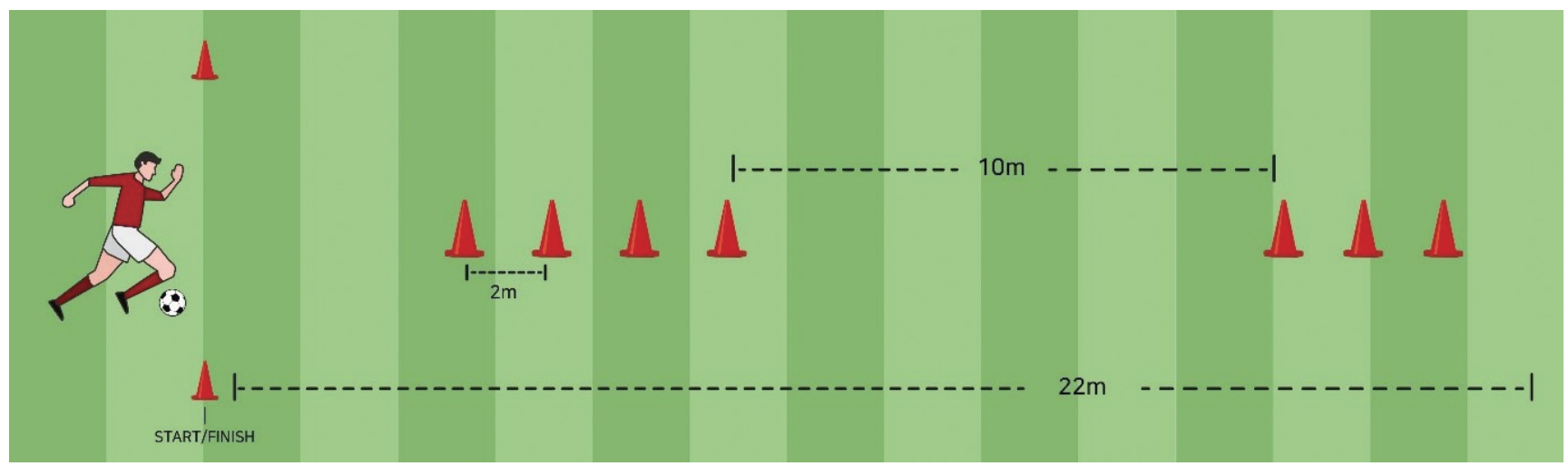

Fig. 3. Coordination test.

Table 3. Results of comparing the differences in physical performance according to the Functional Movement Screen (FMS) total scores

\begin{tabular}{lccc}
\hline Variable & Group & Mean \pm SD & $P$-value \\
\hline 10-m sprint test (sec) & High FMS $(n=10)$ & $1.7 \pm 0.0$ & $0.014^{*}$ \\
& Low FMS $(n=10)$ & $1.8 \pm 0.0$ & \\
30-m sprint test (sec) & High FMS $(n=10)$ & $4.2 \pm 0.1$ & $0.002^{* *}$ \\
& Low FMS $(n=10)$ & $4.4 \pm 0.1$ & \\
Arrowhead agility test (right, sec) $)$ & High FMS $(n=10)$ & $9.0 \pm 0.3$ & $0.039^{*}$ \\
& Low FMS $(n=10)$ & $9.5 \pm 0.5$ & \\
Arrowhead agility test (left, sec) & High FMS $(n=10)$ & $9.1 \pm 0.3$ & 0.613 \\
& Low FMS $(n=10)$ & $8.7 \pm 2.7$ & \\
Coordination test (sec) & High FMS $(n=10)$ & $16.7 \pm 1.8$ & 0.096 \\
& Low FMS $(n=10)$ & $18.3 \pm 2.2$ & \\
\hline
\end{tabular}

Tested by independent sample $t$-test.

SD, standard deviation.

${ }^{*} P<0.05$. ${ }^{*} P<0.01$.

\section{RESULTS}

The results of comparing the differences in physical performance according to the FMS total scores were as shown in Table 3. The results showed statistically significant differences for the $10-\mathrm{m}(P=0.014)$ and $30-\mathrm{m}$ sprint tests $(P=0.002)$ and the arrowhead agility test (right, $P=0.039$ ) between the two groups. The high FMS group showed faster sprint and arrowhead agility (right) tests results than the low FMS group. However, there were no significant differences in the values for arrowhead agility (left) and coordination tests between the two groups $(P>0.05)$.

The association between the FMS total score and physical performance were analyzed by Kendall's Tau b correlation test (Table 4). The 10-m $(r=-0.444, P=0.017)$ and 30-m $(r=-0.425, P=0.016)$ sprint tests and the arrowhead agility test (right, $r=-0.389, P=$ 0.023 ) showed significant negative correlations. In contrast, the FMS total score did not show a significant correlation with the ar-
Table 4. Correlation between Functional Movement Screen (FMS) total score and physical performance

\begin{tabular}{llllcc}
\hline $\begin{array}{c}\text { FMS total } \\
\text { score }\end{array}$ & $\begin{array}{c}10-m \\
\text { sprint test }\end{array}$ & $\begin{array}{c}30-m \\
\text { sprint test }\end{array}$ & $\begin{array}{c}\text { Arrowhead agility } \\
\text { test (right) }\end{array}$ & $\begin{array}{c}\text { Arrowhead } \\
\text { agility test (left) }\end{array}$ & $\begin{array}{c}\text { Coordination } \\
\text { test }\end{array}$ \\
\hline$r$ & -0.444 & -0.425 & -0.389 & -0.241 & -0.123 \\
$P$-value & $0.017^{*}$ & $0.016^{*}$ & $0.023^{*}$ & 0.157 & 0.469 \\
\hline
\end{tabular}

Tested by Kendall's tau b correlation test.

${ }^{*} P<0.05$.

rowhead agility (left, $r=-0.241, P=0.157$ ) and coordination tests $(r=-0.123, P=0.469)$.

\section{DISCUSSION}

In the present study, differences in physical performance of elite male collegiate soccer players according to the FMS total scores were compared and the association between the FMS total score and physical performance was investigated. We found that players with higher FMS total scores had faster records in the 10-m and 30-m sprint tests and the arrowhead agility test (right), and these physical performance factors were found to be significantly associated with the FMS total score.

In soccer, sprinting is one of the most commonly performed actions before scoring (Haugen et al., 2014). In a typical soccer match, approximately $96 \%$ of sprinting involves a distance shorter than $30 \mathrm{~m}$ (Bangsbo, 1994). The motion of sprinting involves the participation of various biomechanical factors throughout the body (Mero et al., 1992), while efficient and fast execution of sprint action requires not only strength but also sufficient mobility and stability (García-Pinillos et al., 2015; Nesser et al., 2008; Seitz et al., 2014). The FMS is a tool designed to assess movement, and the individual tests included in the FMS have a balance between mobility and stability as a basic requirement (Lee et al., 
2018). Therefore, higher FMS total scores could have a positive effect on sprint time records. Movements performed in some FMS tests have the same characteristics required for sprinting in soccer. The deep squat in the FMS is involved in power movements of the lower extremities, while the hurdle step involves proper stride mechanics in the stepping motion, along with mobility and stability of the hips, knees, and ankles (Cook et al., 2014).

Meanwhile, soccer players change running direction every 2-4 seconds, and a total of 1,200-1,400 times during a single match (Turner and Perry, 2014). Accordingly, it can be viewed that agility is important to effectively execute such movements that are required frequently during a match. In the present study, higher FMS total scores were associated with higher values in the arrowhead agility test, which was consistent with the findings of Atalay et al. (2018) and Lloyd et al. (2015). Atalay et al. (2018) reported that the FMS total scores for handball players have a significant negative correlation with the Illinois agility test values. According to Lloyd et al. (2015), reactive agility of soccer players has a significant negative correlation not only with the FMS total score, but also with deep squat, hurdle step, and in-line lunge scores. For agility, muscle quality in the lower extremities, especially leftright muscle imbalance, is important. According to Young et al. (2002), muscle imbalance in the lower extremity has a negative impact on changing direction with speed. The deep squat, hurdle step, and in-line lunge tests in the FMS are all designed to assess muscle imbalance in the lower extremities. In the present study, the high FMS group showed higher scores in these tests, which had a positive impact on the arrowhead agility test (right) values.

However, there were no significant differences between the two groups for the coordination test, while also showing no significant association with the FMS total score. It is believed that such results could be attributed to the fact that, unlike other tests, the coordination test was the only test that required the players to dribble the ball during the test, and as a result, technical factors involved in controlling the ball may have had a bigger influence on the results than basic movements of the players. Because all subjects in the present study were elite level players who have participated in soccer training for a several years, there should have been no major differences in technical factors. Such aspects should be examined in future studies.

The present study had some limitations. Firstly, the present study included only elite male collegiate soccer players; thus, it may be necessary to conduct studies with subjects with diverse characteristics, including sex, age, and/or skill level (amateur or professional). Secondly, the measurement and assessment of physical perfor- mance in the present study were focus only on on-field performance. For example, muscle strength measurement or motion analysis using an isokinetic dynamometer and tensiomyography in laboratory settings were not performed in the present study. Such limitations should be addressed in future studies.

Our findings suggest that a higher FMS total score in players could have a positive impact on their physical performance. Therefore, it is necessary for coaches and trainers to perform the FMS measurements and assessments on the field to closely monitor the FMS total scores of the players. For players with low FMS total scores, training programs designed to take corrective measures on functional deficiency or asymmetric movement patterns should be implemented to help improve physical performance.

\section{CONFLICT OF INTEREST}

No potential conflict of interest relevant to this article was reported.

\section{ACKNOWLEDGMENTS}

This paper was supported by Woosuk University.

\section{REFERENCES}

Atalay ES, Tarakci D, Algun C. Are the functional movement analysis scores of handball players related to athletic parameters? J Exerc Rehabil 2018;14:954-959.

Bangsbo J. The physiology of soccer--with special reference to intense intermittent exercise. Acta Physiol Scand Suppl 1994;619:1-155.

Bonazza NA, Smuin D, Onks CA, Silvis ML, Dhawan A. Reliability, validity, and injury predictive value of the functional movement screen: a systematic review and meta-analysis. Am J Sports Med 2017;45:725732.

Chapman RF, Laymon AS, Arnold T. Functional movement scores and longitudinal performance outcomes in elite track and field athletes. Int J Sports Physiol Perform 2014;9:203-211.

Chorba RS, Chorba DJ, Bouillon LE, Overmyer CA, Landis JA. Use of a functional movement screening tool to determine injury risk in female collegiate athletes. N Am J Sports Phys Ther 2010;5:47-54.

Cook G, Burton L, Hoogenboom BJ, Voight M. Functional movement screening: the use of fundamental movements as an assessment of function - part 1. Int J Sports Phys Ther 2014;9:396-409.

Frost DM, Beach TA, Callaghan JP, McGill SM. Using the Functional Movement Screen ${ }^{\mathrm{TM}}$ to evaluate the effectiveness of training. J Strength Cond 
Res 2012;26:1620-1630.

García-Pinillos F, Ruiz-Ariza A, Moreno del Castillo R, Latorre-Román PÁ. Impact of limited hamstring flexibility on vertical jump, kicking speed, sprint, and agility in young football players. J Sports Sci 2015; 33:1293-1297.

Haugen T, Tønnessen E, Hisdal J, Seiler S. The role and development of sprinting speed in soccer. Int J Sports Physiol Perform 2014;9:432-441.

Imai A, Kaneoka K, Okubo Y, Shiraki H. Effects of two types of trunk exercises on balance and athletic performance in youth soccer players. Int J Sports Phys Ther 2014;9:47-57.

Joo $\mathrm{CH}$. The effects of short-term detraining on exercise performance in soccer players. J Exerc Rehabil 2016;12:54-59.

Kiesel K, Plisky PJ, Voight ML. Can serious injury in professional football be predicted by a preseason functional movement screen? N Am J Sports Phys Ther 2007;2:147-158.

Lee CL, Hsu MC, Chang WD, Wang SC, Chen CY, Chou PH, Chang NJ. Functional movement screen comparison between the preparative period and competitive period in high school baseball players. J Exerc Sci Fit 2018;16:68-72.

Lehance C, Binet J, Bury T, Croisier JL. Muscular strength, functional performances and injury risk in professional and junior elite soccer players. Scand J Med Sci Sports 2009;19:243-251.

Lloyd RS, Oliver JL, Radnor JM, Rhodes BC, Faigenbaum AD, Myer GD. Relationships between functional movement screen scores, maturation and physical performance in young soccer players. J Sports Sci 2015;33:11-19.

Lockie RG, Moreno MR, Lazar A, Orjalo AJ, Giuliano DV, Risso FG, Davis DL, Crelling JB, Lockwood JR, Jalilvand F. The physical and athletic performance characteristics of division i collegiate female soccer players by position. J Strength Cond Res 2018;32:334-343.

McCall A, Carling C, Nedelec M, Davison M, Le Gall F, Berthoin S, Du- pont G. Risk factors, testing and preventative strategies for non-contact injuries in professional football: current perceptions and practices of 44 teams from various premier leagues. Br J Sports Med 2014;48: 1352-1357.

Mero A, Komi PV, Gregor RJ. Biomechanics of sprint running. A review. Sports Med 1992;13:376-392.

Mokha M, Sprague PA, Gatens DR. Predicting musculoskeletal injury in national collegiate athletic association division II athletes from asymmetries and individual-test versus composite functional movement screen scores. J Athl Train 2016;51:276-282.

Myer GD, Ford KR, Palumbo JP, Hewett TE. Neuromuscular training improves performance and lower-extremity biomechanics in female athletes. J Strength Cond Res 2005;19:51-60.

Nesser TW, Huxel KC, Tincher JL, Okada T. The relationship between core stability and performance in division I football players. J Strength Cond Res 2008;22:1750-1754.

Seitz LB, Reyes A, Tran TT, Saez de Villarreal E, Haff GG. Increases in lower-body strength transfer positively to sprint performance: a systematic review with meta-analysis. Sports Med 2014;44:1693-1702.

Silva B, Clemente FM, Camões M, Bezerra P. Functional movement screen scores and physical performance among youth elite soccer players. Sports (Basel) 2017;5(1). pii: E16. https://doi.org/10.3390/sports5010016.

Smith PD, Hanlon MP. Assessing the effectiveness of the functional movement screen in predicting noncontact injury rates in soccer players. J Strength Cond Res 2017;31:3327-3332.

Turner A, Stewart P. Strength and conditioning for soccer players. Strength Cond J 2014;36:1-13.

Young WB, James R, Montgomery I. Is muscle power related to running speed with changes of direction? J Sports Med Phys Fitness 2002;42: 282-288. 